\title{
Prevalence of Congenital Heart Disease in Neonate in a Tertiary Level Hospital
}

\author{
Islam MN,$^{1 *}$ Hossain MA, ${ }^{1}$ Khaleque $M A,{ }^{2}$ Das $M K,{ }^{1}$ \\ Khan MRH, ${ }^{1}$ Bari MS, ${ }^{3}$ Bhuiyan $M_{K} J^{4}$ \\ ${ }^{1}$ Dept. of Neonatology, ${ }^{2}$ Dept. of Paediatrics, ${ }^{3}$ Dept. of Cardiology, Mymensingh Medical College, Mymensingh, \\ Bangladesh, ${ }^{4}$ Dept. of Agricultural Statistics, Bangladesh Agricultural University, Mymensingh, Bangladesh
}

\author{
*Corresponding Author: \\ Dr. Md. Nazrul Islam \\ Assistant Professor \\ Dept. of Neonatology \\ Mymensingh Medical College, Mymensingh, Bangladesh \\ E-mail: mnislamdr1@yahoo.com

\section{Citation} \\ Islam MN, Hossain MA, Khaleque MA, Das MK, \\ Khan MRH, Bari MS, Bhuiyan MKJ. Prevalence of \\ Congenital Heart Disease in Neonate in a Tertiary \\ Level Hospital. Nepal Journal of Medical sciences \\ 2013;2(2):91-5.
}

\section{Background:}

Congenital heart disease (CHD) is defined as a gross structural abnormality of heart or intrathoracic great vessels that is actually or potentially of functional significance. ${ }^{1}$ It is the most common cause of major congenital anomalies, representing a major global health problem. Twenty eight

\begin{abstract}
Background: Congenital heart disease (CHD) has already been recognized as one of the important cause of neonatal mortality and morbidity. The reported prevalence of CHD in live newborns tends to vary a lot due to various unrecognizable lesions at birth and lack of technical expertise.
\end{abstract}

Methods: A cross sectional study was carried out in the department of Neonatology at Mymensingh Medical College Hospital (MMCH), Bangladesh from January to December 2010 to find prevalence of CHD in neonates.

Results: Out of 6560 admitted neonates, 51 were found to have CHD. The prevalence was 7.8/1000 live births. Mean age was 10.2 \pm 9.8 days and weight was $2380.5 \pm 590.5 \mathrm{gms}$. Respiratory distress was the commonest symptom (71\%) followed by cyanosis (26\%) and reluctant to feed $(24 \%)$. Among the CHD Ventricular septal defect (VSD) was the commonest 15/51 and then Atrial septal defect (ASD) 12/51, Patent ductus arteriosus (PDA) 5/51, Transposition of great arteries ( TGA) 4/51, Complex heart disease 4/51 and Tetralogy of Fallot (TOF) 3/51 cases. Some associated non-cardiac anomalies like Down's syndrome, polydactyly, syndactyly, cleft lip, cleft palate and cataract were found. Risk factors associated with CHD were diabetes mellitus (10\%), hypertension ( $8 \%$ ) and maternal infection (4\%). Among the drugs, anti-pyretic by $20 \%$, anti-emetic by $18 \%$, anti-epileptic by $4 \%$, vitamin-A and hormone each by $2 \%$ of mothers respectively.

Conclusion: VSD and ASD were the commonest CHD in this study. Thorough clinical examination and proper investigations immediately after admission is essential, which may help us for proper counseling and early intervention.

Keywords: Congenital; heart disease; prevalence

percent of all major congenital anomalies consist of heart defect. $^{2}$ Prevalence of congenital heart disease is the rate of new cases of congenital heart disease, usually expressed as the number of babies born with congenital heart disease per 1,000 live births. The prevalence of congenital heart defects in neonates has been studied thoroughly and is 
usually reported to be $5-8 / 1000 \cdot^{3-5} \quad$ Asian race is found to be more affected than non Asian race due to high rate of consanguineous marriages. ${ }^{6}$ A study done at Aga Khan University hospital by Hassan showed prevalence rate of CHD up to 4/1000 live births in Karachi. ${ }^{7}$ Same as that reported in India. ${ }^{8}$ Prevalence of congenital heart disease depends upon some factors; like-nature of the study center (whether it is a tertiary level hospital where all critical obstetrical case were admitted), nature of the sample (all live births or all births), source of information (Birth or death certificate), spot examination by a pediatric cardiologist, whether echocardiography is done for all suspected neonates or those who has risk of having CHD ( Baby of diabetic mother, Down's syndrome and other congenital anomaly) etc. ${ }^{9,10}$ Prevalence of congenital heart disease is underestimated due to home deliveries and early discharge of mothers along with their neonates from hospitals without proper neonatal examination pertinent to cardiovascular system by a qualified and experienced person. ${ }^{11}$ Over time the reported total congenital heart disease with prevalence increased substantially from $<1$ per 1,000 live births in 1930 to 9 per 1,000 live births in recent years. With a worldwide annual birth rate around 150 million births. The increase in reported total CHD birth prevalence over time may be caused by changes in diagnostic methods and screening modalities rather than representing a true increase. ${ }^{12}$ Prevalence of CHD in Bangladesh still is unknown due to insignificant population survey. In the present prospective study we will make specific efforts to detect all possible cases of CHD in neonates by examining all neonates admitted in SCANU of $\mathrm{MMCH}$, Bangladesh. There is no authentic data regarding the prevalence of CHD at national level and it is almost nil in this hospital. As this is a tertiary level hospital, where all high risk pregnancies were admitted for delivery and its catchments area is very large which covers about 30 million populations. This factors increase the load of patient which ultimately increase the prevalence of CHD in infancy in this center.

\section{Methods:}

This is a cross sectional analytic study carried out for one year (January to December 2010) in the department of neonatology of $\mathrm{MMCH}$, Bangladesh. Six thousand five hundred sixty neonates were admitted during this period. A thorough clinical examination was carried out within first 24 hours of admission. CHD was suspected in the presence of following criteria defined by Mitchell et al. ${ }^{1}$ Presence of cardiac murmur, presence of cyanosis or feeding difficulty only, cyanosis associated with feeding difficulty, presence of congestive heart failure or failure to thrive. Detailed history was collected from parents or attendant regarding family history of congenital heart disease in siblings, parents. Any significant history of ingestion of drugs, hormone, exposure to radiation, any history of fever with rash prior 6 months of conceptions and in $1^{\text {st }}$ trimester, maternal age and parity. Babies birth weight, age, sex and gestational age were recorded. All suspected patients were investigated with chest X-ray, electrocardiogram and 2D, M-mode echocardiography with color doppler. Baby of diabetic mothers, all Down's syndrome baby and baby with congenital malformations were screened additionally. Innocent murmur or patients with transient systolic murmur were excluded from the study after confirmation of congenital heart defect by echocardiography.

Result: Out of 6560 admitted neonates, 51 were found to have CHD. The prevalence was 7.8/1000 live births. The other findings are given following:

Table 1 : General characters of the study population $(n=51)$

$\begin{array}{lc}\text { Age (Days. Mean } \pm \text { SD) } & 10.2 \pm 9.8 \\ \text { Admission weight }(\text { gm, } & 2380.5 \pm 590.5 \\ \text { mean } \pm \text { SD) } & (1500-3500 \text { gm })\end{array}$

Sex distribution:

Male

$28(55 \%)$

Female

$23(45 \%)$

\section{Gestational age:}

Preterm $21(41 \%)$

Term $30(59 \%)$

Table 1 shows distribution of CHD by birth weight, gestational period and age. Twenty one patients had gestational ages less than 37 completed weeks and 30 neonates had $>37$ weeks. It also shows that male were more than the female.

Table 2: Presentation of congenital heart disease on admission $(\mathrm{n}=51)$

\begin{tabular}{lc}
\hline Presentation & No. of Patient \\
\hline Respiratory distress & $36(71 \%)$ \\
Cyanosis & $13(26 \%)$ \\
No cyanosis & $38(75 \%)$ \\
Reluctant to feed & $12(24 \%)$ \\
Heart failure & $02(4 \%)$ \\
\hline
\end{tabular}


Table 2 shows respiratory distress was the commonest symptom $(71 \%)$ followed by cyanosis $(26 \%)$ and reluctance to feed $(24 \%)$.

Table 3: Types of structural defects of CHD in newborns $(\mathrm{n}=51)$

\begin{tabular}{lc}
\hline Structural Defect & $\begin{array}{c}\text { No. of Patient } \\
(\%)\end{array}$ \\
\hline Ventricular septal defect (VSD) & $15(29)$ \\
Atrial septal defect (ASD) & $12(24)$ \\
Patent ductus arteriosus (PDA) & $05(10)$ \\
Complex congenital heart disease & $04(8)$ \\
Transposition of great arteries (TGA) & $04(8)$ \\
Tetralogy of Fallot (TOF) & $03(6)$ \\
Aortic valve stenosis & $01(2)$ \\
Pulmonary atresia with PDA & $01(2)$ \\
Pulmonary stenosis & $01(2)$ \\
Dextrocardia & $01(2)$ \\
A-V canal defect & $01(2)$ \\
Mitral valve prolapse with MR & $01(2)$ \\
Severe pulmonary hypertension with & $01(2)$ \\
TR & $01(2)$ \\
Persistent truncus arteriosus & \\
\hline
\end{tabular}

Table 3 shows types of structural defect in newborns. VSD was the commonest $29 \%$ cases, ASD in $24 \%$, PDA in $10 \%$, TGA in $8 \%$, complex heart disease in $8 \%$, TOF $6 \%$ cases.

Table 4: Associated non cardiac anomalies $(n=51)$

\begin{tabular}{lc}
\hline \multicolumn{1}{c}{ Anomaly } & $\begin{array}{c}\text { No. of } \\
\text { Patient (\%) }\end{array}$ \\
\hline Down's syndrome & $03(6)$ \\
Polydactyly with syndactyly & $02(4)$ \\
Cleft lip with palate & $01(2)$ \\
Cataract & $01(2)$ \\
Renal anomaly & $01(2)$ \\
Total & $08(16 \%)$ \\
\hline
\end{tabular}

Table 4 shows associated non-cardiac anomalies. Down's syndrome was noticed in $3(6 \%)$ cases, polydactyly and syndactyly were detected in 2 (4\%) newborn. Cleft lip with palate, cataract and renal anomaly were also found in $2 \%$ cases respectively.

Table 5: History of drugs and Diseases during pregnancy $(\mathrm{n}=51)$

\begin{tabular}{llc}
\hline \multicolumn{1}{c}{ Variable } & $\begin{array}{c}\text { Type of drug and disease } \\
\text { during pregnancy }\end{array}$ & $\begin{array}{c}\text { Total } \\
\text { Mothers }\end{array}$ \\
\hline $\begin{array}{l}\text { History of } \\
\text { disease during } \\
\text { pregnancy }\end{array}$ & No disease & 40 \\
& Diabetes mellitus & 05 \\
& Maternal infection & 04 \\
& No H/O drug ingestion & 02 \\
Drug history & Anti-pyretics & 10 \\
during & Anti-emetics & 09 \\
pregnancy & Anti-epileptics & 02 \\
& Vitamin-A & 01 \\
\hline
\end{tabular}

Table 5 shows pattern of risk factors in suspected cases of congenital heart disease. Gestational diabetes mellitus was noticed in $10 \%$ cases, Hypertension in $8 \%$ cases, drug intake like anti-epileptics, anti-pyretics, anti-emetics, vitamin-A, hormone was found in $44 \%$ cases.

\section{Discussion:}

Congenital heart disease has already been recognized as one of the important cause of neonatal mortality and morbidity. Ferencz et. al., reviewed seven major studies from Europe and North America and concluded that confirmed CHD prevalence had been remarkably constant at 4/1000 live births over 40 years time span from 1940-1980. ${ }^{11}$ The prevalence in the present study is 7.8/1000 live births, which is a bit higher than any other study. In this study male and female ratio was 1.2:1. This gender distribution correlates partially with observation of Mollah et. al. ${ }^{12}$

Clinically respiratory distress $(71 \%)$ was the commonest presenting symptom followed by cyanosis (26\%) and reluctant to feed $(24 \%)$. Similar observation was found by others..$^{9,16-18}$ In our study the important CHD in order of frequency were found VSD (29\%), ASD (24\%), PDA (10\%), complex congenital heart disease $(8 \%)$, TGA $(8 \%)$, TOF $(6 \%)$ respectively. The commonest type of congenital heart 
disease was ventricular septal defect. This correlates with the study of Mitchelle et. al. ${ }^{1}$ Mollah et. al. ${ }^{12}$ and Hussain et. al. ${ }^{20}$ A study conducted on Delhi school children to find out prevalence of congenital heart disease showed lesions in order of frequency were VSD 30\%, ASD 23\%, PDA $11 \%$, TOF $4 \%{ }^{20}$ Findings of that study are almost similar to our study. Report of New England regional infant cardiac program showed VSD as the commonest lesion, which is similar to our study. ${ }^{22}$ But our study differs from Rahman et. al. ${ }^{23}$, Siddique et. al. ${ }^{24}$ and Fatema et. al. ${ }^{25}$ They found ASD was the commonest lesion. This difference in observation might due to that Rahman et. al. and Siddique et. al. included many adult patients in their study. A significant proportion of VSD close spontaneously before adulthood and some untreated patients with large VSD die in childhood from heart failure. On the other hand ASD patients may remain asymptomatic in childhood and are diagnosed for the first time when they are adult. The study subjects of Fatema et. al. were all newborn and many small sized VSD and most of the child with TOF may not manifest by that time. ${ }^{25}$

In our study associated non-cardiac anomaly and somatic anomaly was noticed in 16\% cases. Among those Down's syndrome were noticed in $6 \%$ newborn with congenital heart disease. This is almost similar to other studies. ${ }^{10,26}$ Maternal disease like diabetes mellitus, maternal infection, hypertension and some drugs might increase occurrence of heart disease in neonates. Regarding the history of diseases during pregnancy, it was found that 40 (78\%) mothers of affected neonates had no history of disease during pregnancy period. While $10 \%$ mothers were diabetic, $8 \%$ hypertensive and $4 \%$ mothers gave a positive history of suggestive of infection during their pregnancy period.

History of drug intake during pregnancy revealed that $55 \%$ mothers had no history of drug ingestion during pregnancy, while $22(44 \%)$ mothers had a positive history of ingestion of drugs. Among drugs anti-pyretic were taken by $20 \%$ mothers, anti-emetic by $18 \%$, anti-epileptic by $4 \%$, vitamin-A and hormone each were taken by $2 \%$ of mothers. Similar observation was found by Fatema et. al. ${ }^{27}$ This is a single hospital based study to find out the prevalence of CHD.

\section{Conclusion:}

Our observations show, prevalence of CHD was 7.8/1000 live birth. VSD and ASD were the commonest heart diseases. A good number of mothers have got some definite diseases, like diabetes mellitus, hypertension and maternal infection in this study. Early diagnosis of disease and proper counseling of the parents will help in early intervention and reduce mortality and morbidity of neonates.

\section{References:}

1. Mitchell SC, Korones SB, Berendes HW. Congenital heart disease in 56,109 births. Incidence and natural history. Circulation 1971;43:323-32.

2. Dolk H, Loane M, Garne E. For the European Surveillance of Congenital Anomalies (EUROCAT) working Group. Congenital heart defects in Europe: prevalence and perinatal mortality, 2000-2005. Circulation 2011;123:841-9.

3. Samanek M, Voriskova M. Congenital heart disease among 815,569 children born between 1980 and 1990 and their 15 year survival: a prospective Bohemia survival study. Pediatr Cardiol 1999;20:411-17.

4. Wren C, Richmond S, Donaldson L. Presentation of congenital heart disease in infancy: implications for routine examination. Arch Dis Child Fetal Neonatal Ed. $1999 ; 80: 49-53$

5. Wren C, Richmond S, Donaldson L. Temporal variability in birth prevalence of cardiovascular malformations. Heart 2000;83:414-19.

6. Sadiq M, Stümper O, Wright JG, et al. Influence of ethnic origin on the pattern of congenital heart defects in the first year of life. Br Heart J 1995;73:173-6.

7. Hassan I, Haleem AA, Bhutta ZA. Profile and risk factors for congenital heart disease. J Pak Med Assoc $1997 ; 47: 78-81$

8. Chadha SL, Singh N, Shukla DK. Epidemiological study of Congenital heart disease. Indian $\mathrm{J}$ Pediatr. 2001;68:507-10.

9. Khalil A, Agarwal R, Thirupuran S, et al. Prevalence of congenital heart disease among hospital live births in India. Indian pediatrics 1994;31:519-26.

10. Hoffman JIE. Congenital heart disease: Prevalence and inheritence. Pediatr clin North Amer 1990; 37: 25 - 43.

11. Ferencz C, Rubin JD, Meconter RJ. Congenital Heart Diseases. Prevalence at live birth. The Baltimore Washington infant study. Am J Epidemiol 1985;121:3136.

12. Mollah MAH, begum NA, Islam MN, et al. Clinical profile of congenital heart diseases (CHD): an Analysis of 218 cases. Bangladesh Heart J 2002;17:62-7. 
13. Hoffman JI. Prevalence of congenital heart disease: I. Postnatal prevalence, Pediatr Cardiol 1995;16:103-13.

14. Edler I., Lindstrom K. The history of echocardiography. Ultrasound Med Biol 2004;30:1565644.

15. Rauh LW. The prevalence of organic heart disease in school children. Am Heart J 1930;18:705-7.

16. Vashishtha VM, Kalra A, Jain VK. Prevalence of congenital heart disease in school children. Indian Pediatrics 1993;30:1337-40.

17. Ejaz MS, Billo AG. Clinical Pattern of Herat diseases in children. J Choll Physicians Surg Pak 2000;10:10-2.

18. Shermin LS, Hoque MA, Iqbal M, et al. Pattern and clinical profile of congenital heart disease in a teaching hospital. TAJ 2008;21:58-62.

19. Hag El. Pattern of congenital heart disease in Sudanese children. East Afr Med J. 1994;71:580-6.

20. Hussain M, Hossain M, Amin SK, et al. Pattern of congenital heart disease in Dhaka Shishu Hospital. DS (Child) H J 1992;8:35-46.

21. Radzik D, Davignon A, Van Doesburg N. Predictive factors for spontaneous closure of atrial septal defects diagnosed in the first 3 months of life. J Am coll cardiol $1993 ; 22: 851-3$.

22. Report of the New England Regional Infant cardiac program. Paediartics 1980;65:377-461.

23. Rahman S, Ahmed MN, Rahmatullah KHI, et al. The prevalence of congenital heart diseases diagnosed by Non-invasive technique- Ten years study in Bangladesh. DS (Child) H J. 1992;8:5-15.

24. Siddique FM, Kamal SMM, Huq KMHSS. Clinical presentation of congenital heart diseases in hospitalized patients. Bangladesh Heart Journal 1989;4:13-17.

25. Begum NNF, Ahmed QS. Pattern of heart diseases among neonates and their outcome: One year experience in non-invasive cardiac laboratory of combined military hospital, Dhaka. Bangladesh J child health 2001; 25:4852.

26. Bound JP, Logan WF. Prevalence of congenital heart disease in black pool: 1957-1971. Brit Heart J 1977; 39:445-50.

27. Fatema NN, Chowdhury RB, Chowdhury L. Prevalence of congenital heart disease among hospital live birth in a tertiary hospital of Bangladesh. CVJ 2008;1:14-20. 